\title{
Role of IL-18 Gene Promoter Polymorphisms, Serum IL-18 Levels, and Risk of Hepatitis B Virus-related Liver Disease in the Guangxi Zhuang Population: a Retrospective Case-Control Study
}

\author{
Yu Lu ${ }^{\star}$, Jin-Gui Bao ${ }^{\star}$, Yan Deng ${ }^{\star}$, Cheng-Zhi Rong, Yan-Qiong Liu, Xiu-Li \\ Huang, Liu-Ying Song, Shan Li*, Xue Qin*
}

\begin{abstract}
Background: The aim of this study was to assess the relationship between IL-18 gene polymorphisms and HBV-related diseases and whether these polymorphisms influence its expression in the Guangxi Zhuang population. Materials and Methods: We enrolled 129 chronic $\mathrm{HBV}$ infected (CHB) patients, $86 \mathrm{HBV}$-related liver cirrhosis (LC) patients and 160 healthy controls in our study. Polymerase chain reaction-restriction fragment length polymorphism methods were used to detect IL-18 gene -607C/A, -137G/C polymorphisms, and an ELISA kit was employed to determine serum IL-18 levels. Results: No correlation was found between the -607C/A polymorphism and risk of $\mathrm{HBV}$-related disease. For the $-137 \mathrm{G} / \mathrm{C}$ polymorphism, the GC genotype and $\mathrm{C}$ allele were associated with a significantly lower risk of CHB (95\% CI: $0.32-0.95, p=0.034$ and $95 \%$ CI: $0.35-0.91$, $p=0.018)$ and HBV-related LC (95\% CI: $0.24-0.89, p=0.022$ and 95\% CI: 0.28-0.90, $p=0.021)$. A similar decreased risk was also found with the $\mathrm{A}-607 \mathrm{C}-137$ haplotype. With respect to $\mathrm{IL}-18$ expression, it was significantly lower in both patient groups, but no association was noted between the two polymorphisms in the IL-18 gene and its expression. Conclusions: Our study indicated that the $-137 \mathrm{C}$ allele in the IL-18 gene may be a protective factor for HBV-related disease, and serum IL-18 level may be inversely associated with CHB and HBV-related LC.
\end{abstract}

Keywords: Interleukin-18, polymorphism - expression - chronic hepatitis B - Liver cirrhosis

Asian Pac J Cancer Prev, 16 (14), 6019-6026

\section{Introduction}

Although highly effective vaccines against hepatitis B virus (HBV) have been available since 1982, HBV infection remains the tenth leading cause of death worldwide, accounting for 500 thousand to 1.2 million deaths annually (Lavanchy, 2004). The cause of death ranges widely and includes fulminant hepatic failure, liver cirrhosis (LC), and hepatocellular carcinoma (HCC) (Perrillo, 2002; Wang et al., 2003), indicating that the clinical outcome of the infection varies greatly among individuals. Numerous risk factors for the development of such HBV-related liver diseases have been identified in addition to $\mathrm{HBV}$ infection, including exposure to aflatoxins and alcohol and tobacco abuse (Moradpour and Blum, 2005; McKillop et al., 2006). Recently, studies have focused on cytokine mutation and have identified multiple roles of cytokine polymorphisms in HBV clearance as well as in clinical outcomes (Tuncbilek, 2014). Interleukin-18 (IL-18) has been shown to play a major role.
IL-18 is a potent pro-inflammatory member of the IL-1 cytokine superfamily which is broadly produced by macrophages, dendritic cells, Kupffer cells, endothelial cells, and vascular smooth muscle cells (Pirhonen et al., 1999). As an immune activator, it plays a key role in mediating the innate and acquired immune responses (Okamura et al., 1998), and has been identified to possess a wide range of functions, including interferon- $\gamma($ IFN- $\gamma$ ) and tumor necrosis factor-alpha (TNF-a) production (Okamura et al., 1995; Nakanishi et al., 2001), enhancing the cytotoxicity of NK cells and FasL expression, and promotion of Th1-type immune responses, among others (Hoshino et al., 1999). The IL-18 gene is located on chromosome 11q22.2-22.3 and consists of six exons and five introns (Kruse et al., 2003). Thus far, several single nucleotide polymorphisms (SNPs) in the promoter region and two polymorphisms in the 5'-nontranslated region of IL-18 have been identified (Giedraitis et al., 2001). Among them, two in the promoter region at loci 607 and 137 are the most studied. Cloning and mutation analysis of this gene in 
the promoter region has demonstrated that a change from allele $\mathrm{C}$ to $\mathrm{A}$ at 607 disrupts the cAMP-responsive elementbinding protein binding site, and that a change from allele $\mathrm{G}$ to $\mathrm{C}$ at 137 interrupts the H4TF-1 nuclear factor binding site. Furthermore, changes in these sites have resulted in the alteration of IL-18 promoter transcription activity, consequently influencing the expression of IL-18 and potentially that of related cytokines such as IFN- $\gamma$ and TNF-a (Giedraitis et al., 2001).

To date, numerous studies have explored the role of IL-18 SNPs in diseases, and a positive relationship between $-607 \mathrm{C} / \mathrm{A}$ and $-137 \mathrm{G} / \mathrm{C}$ (GenBank accession nos. rs1946519 and rs187238) polymorphisms and progression of various diseases has been found, including rheumatoid arthritis (Gracie et al., 2005), type 1 diabetes (Mojtahedi et al., 2006), sarcoidosis (Zhou et al., 2005), and several cancers (Lin et al., 2007; Taheri et al., 2012; Tsai et al., 2013). Clinical research has also revealed a correlation between these two SNPs and an individual's risk of HBV infection. Zhang et al. (Zhang et al., 2005) suggested that the polymorphisms of $-607 \mathrm{C} / \mathrm{A}$ and $-137 \mathrm{G} / \mathrm{C}$ are closely associated with susceptibility to chronic HBV infection (CHB). A study by Chenog et al. (Cheong et al., 2010) also indicated that these polymorphisms are likely associated with HBV clearance in a Korean population.

The association between the two SNPs and susceptibility to HBV seems to be repeatedly observed, as suggested by a recently conducted review (Motavaf et al., 2014). However, two studies on IL-18 polymorphisms with hepatitis B recurrence after liver transplantation found no correlation between them (Wu et al., 2011; Li et al., 2012b). A meta-analysis published in 2014 also revealed a null association in both $-607 \mathrm{C} / \mathrm{A}$ and $-137 \mathrm{G} / \mathrm{C}$ SNPs, indicating conflicting results regarding the role of IL-18 polymorphisms in HBV infection (Xia et al., 2014). On the other hand, in a study carried out in Yunnan province exploring the association between HBV infection and IL-18 polymorphisms in three minority populations, the genotype and allele distributions in both $-607 \mathrm{C} / \mathrm{A}$ and -137G/C SNPs were observed to be significantly different in the three populations, and the HBV susceptibility of these genes was concluded to play varying roles in different ethnicities (Xin-min, 2010). Nevertheless, no related studies have been conducted in Guangxi Zhuang population, which is also a minority population with high HBV prevalence. More recently, serum IL-18 levels were found to be associated with disease severity in patients with viral hepatitis B (Wen et al., 2001), and IL-18 was shown to be remarkably up-regulated in HCC tissue specimens compared to normal tissues (Zhang et al., 2011), but few studies have focused on the effect of IL18 polymorphisms on its expression. In order to assess these problems, we have further evaluated the role of IL$18-607 \mathrm{C} / \mathrm{A}$ and $-137 \mathrm{G} / \mathrm{C}$ polymorphisms in CHB- and HBV-related LC, together with their influence on serum IL-18 levels, in the Guangxi Zhuang population.

\section{Materials and Methods}

Study population

A total of 215 patients who tested positive for the hepatitis B surface antigen (HBsAg) and visited the outpatient clinic of the Gastroenterology Department at the First Affiliated Hospital of Guangxi Medical University (Guangxi, China) between May and December 2013, were recruited into this study. The patients underwent follow-up for at least 6 months with regular measurements of serum alanine aminotransferase (ALT), aspartate aminotransferase (AST), and HBV markers (HBsAg, HBV core antibody, hepatitis e antigen, hepatitis B e antibody), as well as ultrasonography or computed tomography (CT) of the liver. The patients were then categorized into two groups according to the examination results: the CHB group (129 patients) and the HBV-related LC group (86 patients). The criteria for inclusion in the $\mathrm{CHB}$ group were i) HBsAg seropositive over a 6-month period; ii) elevated ALT or AST ( $>2$ times the upper limit of normal) at least once during the follow-up; iii) serum HBV-DNA levels $>1,000$ copies $/ \mathrm{mL}$; and iv) without any other type of liver disease such as chronic hepatitis $\mathrm{C}$ or alcoholic liver disease. The diagnosis of LC was based on typical morphological findings from ultrasonography/CT, combined with their corresponding laboratory features, or evidence of portal hypertension. For comparison, 160 healthy volunteers who visited the general health check-up division of the same hospital served as a control group, with their routine physical examination having indicated them to be positive for hepatitis B surface antibody and hepatitis B core antibody but negative for $\mathrm{HBsAg}$, with normal liver function tests and without any malignancy or other serious illness. Considering the possible confounders, the controls were generally matched to the patients regarding age ( \pm 5 years) and gender, and data concerning smoking habits and alcohol consumption, defined as never and current, was also collected. Written informed consent was obtained from all participants after they received a full explanation of the study, and the study was approved by the Ethics Committee of the First Affiliated Hospital, Guangxi Medical University.

\section{DNA extraction and polymorphism genotyping}

Peripheral venous blood $(2 \mathrm{~mL})$ drawn from all the subjects was used for DNA extraction with a QIAamp DNA blood mini kit (QIAGEN GmbH, Hilden, Germany). Polymorphisms of the target SNPs were analyzed by using the polymerase chain reaction-restriction fragment length polymorphism (PCR-RFLP) method. Briefly, PCR was first conducted to amplify the target DNA, with the forward primer 5'-TCAGTGGAACAGGAGTCCAT-3', reversed primer 5'-GCAGAAAGTGTAAAAATTTTT-3' of $-607 \mathrm{C} / \mathrm{A}$ SNP and forward primer 5'-AGGTGCTTT CTTAAAGTCAGA-3', reversed primer 5'-AATATCA CRATTTTCATGGAA-3' of -137G/C SNP. Following amplification, the PCR product was digested separately with DraI and HinfI restriction enzymes, and the digested fragments were visualized on a $2.5 \%$ agarose gel containing ethidium bromide (Figure 1). To confirm the results of genotyping, approximately $10 \%$ of specimens were randomly selected to be directly sequenced by the Sangon Biotech Company (Shanghai, China), and our data was completely consistent with the sequencing results. 
Table 1. Clinical Characteristic of the Study Subjects

\begin{tabular}{|c|c|c|c|c|}
\hline Variable & $\begin{array}{l}\text { Controls } \\
(n=160)\end{array}$ & $\begin{array}{c}\text { CHB } \\
(n=129)\end{array}$ & $\begin{array}{c}\mathrm{LC} \\
(\mathrm{n}=86)\end{array}$ & $p$ value \\
\hline $\begin{array}{l}\text { Age }(\text { mean } \pm \text { SD }) \\
\text { Gender }\end{array}$ & $41.2 \pm 12.1$ & $37.9 \pm 11.7$ & $47.7 \pm 10.3$ & $<0.001$ \\
\hline $\begin{array}{l}\text { Male } \\
\text { Female }\end{array}$ & $\begin{array}{c}137(85.6) \\
23(14.4)\end{array}$ & $\begin{array}{c}115(89.1) \\
14(10.9)\end{array}$ & $\begin{array}{l}74(86.0) \\
12(14.0)\end{array}$ & 0.651 \\
\hline \multicolumn{5}{|c|}{ Alcohol consumption } \\
\hline $\begin{array}{l}\text { No } \\
\text { Yes }\end{array}$ & $\begin{array}{c}117(73.1) \\
43(26.9)\end{array}$ & $\begin{array}{l}81(62.8) \\
48(37.2)\end{array}$ & $\begin{array}{l}59(68.6) \\
27(31.4)\end{array}$ & 0.171 \\
\hline \multicolumn{5}{|l|}{ Cigarette smoking } \\
\hline $\begin{array}{l}\text { No } \\
\text { Yes }\end{array}$ & $\begin{array}{l}122(76.2) \\
38(23.8)\end{array}$ & $\begin{array}{l}94(72.9) \\
35(27.1)\end{array}$ & $\begin{array}{l}60(69.8) \\
26(30.2)\end{array}$ & 0.532 \\
\hline
\end{tabular}
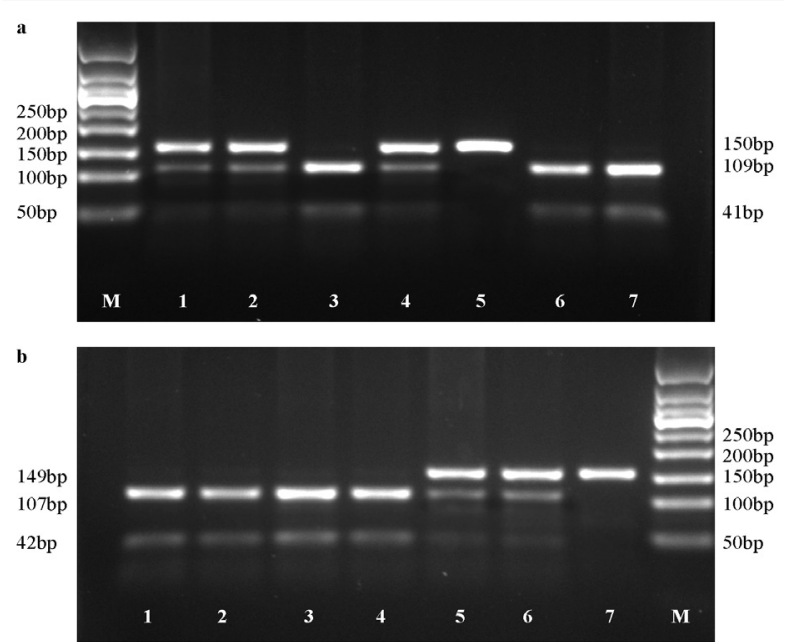

Figure 1. PCR-RFLP assay for Analyzing the -607C/A and -137G/C Polymorphisms of the IL-18 Gene. (a) $-607 \mathrm{C} / \mathrm{A}$ polymorphism. Lanes 1,2 , and 4 show the $\mathrm{AC}$ genotype; Lanes 3, 6, and 7 show the AA genotype; Lane 5 shows the CC genotype. (b) $-137 \mathrm{G} / \mathrm{C}$ polymorphism. Lanes $1-4$ show the GG genotype; Lanes 5 and 6 show the GC genotype; Lane 7 shows the CC genotype. M, marker

Serum samples were collected for all study subjects. When blood samples were obtained, they were collected into serum tubes with an accelerating agent for serum separation and kept at room temperature for 30 minutes before centrifugation for 15 to 25 minutes at a minimum of $2,000 \mathrm{~g}$. Serum was then isolated and stored at $-80^{\circ} \mathrm{C}$ until further use. The IL-18 concentration was detected using a sandwich ELISA kit (Human Interleukin 18 ELISA Kit, Sangon Biotech Company, Shanghai, China) according to the manufacturer's instructions. The detection levels for IL-18 range from 15 to $560 \mathrm{ng} / \mathrm{L}$, and the intra- and inter-assay coefficients of variation in our study were $7.5 \%$ and $8.9 \%$, respectively.

\section{Statistical analysis}

For continuous variables, the mean and standard deviation (SD) were used to describe those normally distributed and one-way analysis of variance (ANOVA) was performed to assess between-group variance. The median and interquartile range (IQR) was used to describe the skewed variables and the Kruskal-Wallis test was conducted to compare the difference among groups. The Student-Newman-Keuls test of pairwise comparisons followed if the results of the one-way ANOVA or KruskalWallis tests were significant. Genotypic frequencies of
$-607 \mathrm{C} / \mathrm{A}$ and $-137 \mathrm{G} / \mathrm{C}$ SNPs were obtained by direct counting. The Hardy-Weinberg equilibrium (HWE), which revealed normal distribution of the population, was performed for both case and control groups using a goodness-of-fit $\chi^{2}$ test. Comparison of the allele and genotype frequencies of the two SNPs in different groups was carried out using the $\chi^{2}$ test or Fisher's exact test, when appropriate. To assess the relative risk conferred by a particular allele and genotype, logistic regression models were used for calculating the odds ratios (ORs) and $95 \%$ confidence intervals (CIs), controlling for age, gender, and smoking and drinking status as covariates. Further, haplotypes and their frequencies for each subject were inferred using the algorithm (PHASE) developed by Stephens et al. (Stephens et al., 2001). All analyses were conducted using the Statistical Package for Social Sciences (SPSS, version 16.0) and statistical significance was set at a two side $P$ value of 0.05 .

\section{Results}

Basic characteristics of the study subjects

A total of 375 unrelated Chinese subjects, including $129 \mathrm{CHB}$ patients, $86 \mathrm{HBV}$-related LC patients, and 160 healthy controls were enrolled in the study, with their basic demographic characteristics summarized in Table 1. There were no significant differences among the control, CHB, and LC groups regarding gender distribution and smoking and alcohol drinking status. However, when considering the mean age, a significant difference was found between the LC group and the other two groups $(P<0.001)$, where the mean age of the LC patients $(47.7 \pm 10.3)$ was found to be approximately 10 years older than the $\mathrm{CHB}$ patients $(37.9 \pm 11.7)$ and healthy controls (41.2 \pm 12.1$)$.

\section{Correlation between the $-607 \mathrm{C} / \mathrm{A}$ polymorphism and risk of $C H B$ - and $H B V$-related $L C$}

The genotype and allele frequencies of the IL-18 gene $-607 \mathrm{C} / \mathrm{A}$ SNP in the control and patient groups are described in Table 2. For the 160 control subjects, the frequencies of the $\mathrm{AA}, \mathrm{AC}$, and $\mathrm{CC}$ genotypes were $25.0,45.6$, and $29.4 \%$, respectively; for the 215 patients, the frequencies of the AA, AC, and $\mathrm{CC}$ genotypes were 24.8, 45.0, and 30.2\%, respectively, in the CHB group and 25.6, 45.3, and 29.1\%, respectively, in the LC group. The genotype frequencies among the three groups were all consistent with the prediction under the condition of the HWE. However, no significant differences in the genotype distribution or in the allele frequency of this polymorphism between cases and controls were observed (all $p>0.05$ ). Binary logistic regression analyses adjusted by age, sex, and smoking and drinking status also showed that the $-607 \mathrm{C} / \mathrm{AAC}$ and $\mathrm{CC}$ genotypes and $\mathrm{C}$ allele were not associated with a risk of CHB $(p=0.789, p=0.912$, and $p=0.887$, respectively). When evaluating the association between the $-607 \mathrm{C} / \mathrm{A}$ SNP and CHB-related LC patients, a similar situation was found (Table 2).

Correlation between $-137 G / C$ polymorphism and risk of $C H B$ - and $H B V$-related $L C$

The genotype and allele frequencies of IL-18 -137G/C 
Yu Lu et al

SNP among the control, CHB, and LC groups are presented in Table 2. For the 160 control subjects, the frequencies of the GG, GC, and CC genotypes were 64.4, 32.5 , and $3.0 \%$, respectively; for the 215 patients, the frequencies of the $\mathrm{GG}, \mathrm{GC}$, and $\mathrm{CC}$ genotypes were 77.5, 20.9 , and $1.6 \%$, respectively, in the CHB group, and 80.2, 18.6 , and $1.2 \%$, respectively, in the LC group. According to the goodness-of-fit $\chi^{2}$ test, the genotype frequencies of the three groups also did not deviate from the HWE (all $p>0.05$ ). A significant difference was found in the genotype distribution and in the allele frequency between the patient groups and the control subjects. Regarding genotypes, the GG type at the -137 loci was significantly higher in LC patients compared to controls $\left(\chi^{2}=6.643\right.$, $p=0.028)$. When regarding alleles, the $\mathrm{C}$ allele of this SNP was significantly lower in both CHB and LC patients compared to controls $\left(\chi^{2}=5.730, p=0.017\right.$ and $\chi^{2}=6.522$, $p=0.011)$. Binary logistic regression analyses adjusted by age, sex, and smoking and drinking status revealed that the GC genotype was significantly associated with risk of CHB- and HBV-related LC compared with the GG genotype (odds ratio (OR): $0.55,95 \%$ confidence interval (CI): $0.32-0.95, p=0.034$ and OR: $0.46,95 \%$ CI: $0.24-$ $0.89, p=0.022$ ). With respect to the $-137 \mathrm{G} / \mathrm{C}$ SNP alleles, the $\mathrm{C}$ allele was also associated with a decreased risk of both HBV-related diseases (OR: 0.56, 95\% CI: 0.35-0.91, $p=0.018$ for CHB, and OR: $0.50,95 \% \mathrm{CI}: 0.28-0.90, p$ $=0.021$ for $\mathrm{LC}$ ).

\section{$H B V$-related LC patients versus $C H B$ patients}

To elucidate and distinguish the effects of SNPs on LC through direct influence on LC progression or indirect influence as induced by $\mathrm{HBV}, \mathrm{CHB}$ patients were also chosen as a control group, and a binary logistic regression model was further developed to estimate ORs to test the association between the two SNPs and the risk of LC compared to $\mathrm{CHB}$ patients. The results indicated that there was no significant difference between $-607 \mathrm{C} / \mathrm{A}$ and $-137 \mathrm{G} / \mathrm{C}$ polymorphisms of IL-18 and risk of LC when using $\mathrm{CHB}$ patients as a control.

\section{Estimated haplotype frequencies and risk of $\mathrm{CHB}$ - and $H B V$-related $L C$}

By using SHEsis software, haplotype analyses of IL-18 SNPs were also performed between patient and control groups to derive haplotypes specifically related with risk of CHB- and HBV-related LC. A total of four haplotypes (A-607C-137, A-607G-137, C-607C-137, and C-607G-137) were derived from the observed genotypes and their distribution in the cases and controls are listed in Table 3. The major haplotype in these three groups was CG, accounting for $47.0,48.4$, and $48.8 \%$ in the control, $\mathrm{CHB}$, and LC groups, respectively. Following haplotype analysis, the $\mathrm{A}^{-607} \mathrm{C}^{-137}$ haplotype was found to be inversely associated with risk of CHB- and HBV-related LC (OR: $0.51,95 \%$ CI: $0.29-0.88, p=0.015$ and OR: $0.50,95 \%$ CI: $0.26-0.95, p=0.031$, respectively). No significant difference was found in the remaining haplotypes.

\section{Comparison of-607C/A and -137G/C genotype frequencies with other populations}

Considering that the $-607 \mathrm{C} / \mathrm{A}$ and $-137 \mathrm{G} / \mathrm{C}$ genotype frequencies might be distinct among diverse populations, the genotype and allele frequencies of the

Table 2. Genotype and Allele Frequencies of IL-18 Gene -607C/A and -137G/C SNPs between HBV-related Patients and Healthy Controls

\begin{tabular}{|c|c|c|c|c|c|c|}
\hline SNPs & $\begin{array}{l}\text { controls } \\
(n=160)\end{array}$ & $\begin{array}{c}\text { CHB } \\
(n=129)\end{array}$ & $\begin{array}{c}\mathrm{LC} \\
(\mathrm{n}=86)\end{array}$ & OR $(95 \% \mathrm{CI})^{\mathrm{a} *}, p$ value & OR $(95 \% \mathrm{CI})^{\mathrm{b} *}, p$ value & OR $(95 \% \mathrm{CI})^{\mathrm{c} *}, p$ value \\
\hline \multicolumn{7}{|c|}{$-607 \mathrm{C} / \mathrm{A}(\mathrm{rs} 1946518)$} \\
\hline AA & $40(25.0)$ & $32(24.8)$ & $22(25.6)$ & $1.0^{\text {ref }}$ & $1.0^{\text {ref }}$ & $1.0^{\mathrm{ref}}$ \\
\hline $\mathrm{AC}$ & $73(45.6)$ & $58(45.0)$ & $39(45.3)$ & $0.92(0.51-1.67) p=0.789$ & $0.88(0.44-1.76) p=0.720$ & $1.06(0.50-2.28) p$ \\
\hline $\mathrm{CC}$ & $47(29.4)$ & $39(30.2)$ & $25(29.1)$ & $1.04(0.54-1.98) p=0.912$ & $0.94(0.45-1.98)$ & $0.84(0.37-1.92)$ \\
\hline A allele & $153(47.8)$ & $122(47.3)$ & $83(48.3)$ & 1.0ref & 1.0ref & 1.0ref \\
\hline $\mathrm{C}$ allele & $167(52.2)$ & $136(52.7)$ & $89(51.7)$ & $1.03(0.73-1.43) p=0.887$ & $0.97(0.66-1.43) p=0.973$ & $0.90(0.59-1.39) p=0.640$ \\
\hline$P^{\text {-HWE }}$ & 0.287 & 0.265 & 0.394 & & & \\
\hline \multicolumn{7}{|c|}{$-137 \mathrm{G} / \mathrm{C}(\mathrm{rs} 187238)$} \\
\hline GG & $103(64.4)$ & $100(77.5)$ & $69(80.2)$ & $1.0^{\mathrm{ref}}$ & $1.0^{\mathrm{ref}}$ & $1.0^{\text {ref }}$ \\
\hline GC & $52(32.5)$ & $27(20.9)$ & $16(18.6)$ & $0.55(0.32-0.95) p$ & $0.46(0.24-0.89) p$ & $0.94(0.44-2.00)$ \\
\hline $\mathrm{CC}$ & $5(3.0)$ & $2(1.6)$ & $1(1.2)$ & $0.41(0.08-2.24) p=0.305$ & $0.37(0.04-3.43) p=0.381$ & $0.49(0.04-6.45) p=0.590$ \\
\hline G allele & $258(80.6)$ & $227(88.0)$ & $154(89.5)$ & $1.0^{\mathrm{ref}}$ & $1.0^{\mathrm{ref}}$ & $1.0^{\text {ref }}$ \\
\hline $\mathrm{C}$ allele & $62(19.4)$ & $31(12.0)$ & $18(10.5)$ & $0.56(0.35-0.91) p=0.018$ & $0.50(0.28-0.90) p=0.021$ & $0.90(0.46-1.77) p=0.759$ \\
\hline$P^{\text {-HWE }}$ & 0.611 & 0.909 & 0.947 & & & \\
\hline
\end{tabular}

a CHB patients versus healthy controls; b LC patients versus healthy controls; c LC patients versus CHB patients; *Adjusted for sex, age, smoking and drinking status by logistic regression model

Table 3. Frequencies of the Haplotypes formed by -607C/A and -137G/C SNPs in HBV-related Patients and Healthy Controls

\begin{tabular}{|c|c|c|c|c|c|c|c|}
\hline Haplotype & Controls $(2 \mathrm{n}=320, \%)$ & $\mathrm{CHB}(2 \mathrm{n}=258, \%)$ & OR $(95 \% \mathrm{CI})$ & $p$ & $\mathrm{LC}(2 \mathrm{n}=172, \%)$ & OR $(95 \% \mathrm{CI})$ & $p$ \\
\hline $\mathrm{A}^{-607} \mathrm{C}^{-137}$ & $45(14.2)$ & $20(7.8)$ & $0.51(0.29-0.88)$ & 0.015 & $13(7.6)$ & $0.50(0.26-0.95)$ & 0.031 \\
\hline $\mathrm{A}^{-607} \mathrm{G}^{-137}$ & $108(33.6)$ & $102(39.5)$ & $1.29(0.92-1.82)$ & 0.139 & $70(40.7)$ & $1.35(0.92-1.98)$ & 0.121 \\
\hline$C^{-607} C^{-137}$ & $17(5.2)$ & $11(4.3)$ & $0.82(0.38-1.79)$ & 0.620 & $5(2.9)$ & $0.54(0.19-1.50)$ & 0.229 \\
\hline $\mathrm{C}^{-607} \mathrm{G}^{-137}$ & $150(47.0)$ & $125(48.4)$ & $1.06(0.76-1.47)$ & 0.736 & $83(48.8)$ & $1.08(0.74-1.56)$ & 0.691 \\
\hline
\end{tabular}


two polymorphisms in our control group were further compared with those from the Haplotype Map (HapMap) project (http://www.ncbi.nlm.nih.gov/snp/) and previous reports (El-Serag and Rudolph, 2007). The data in Table 4 shows that the allele frequency of -607C/A in CEU (Utah residents with northern and western European ancestry), JPT (Japanese in Tokyo, Japan), and YRI (Yoruba in Ibadan, Nigeria) populations were significantly different from those in the current study. There was a significantly higher rate of the $\mathrm{C}$ allele in the $\mathrm{CEU}$ and YRI populations, but a lower rate in the JPT population, compared with that in the present study. The CC genotype was also significantly higher in the YRI population, while no significant difference in genotypes was found between the remaining populations and the current study. Regarding the $-137 \mathrm{G} / \mathrm{C}$ site, the genotype and allele distribution in AFR (African American descent), CHN (Chinese descent), and $\mathrm{HCH}$ (Han Chinese in Hubei province, China) populations was not significantly different from those of our study. However, for the EUR (European American descent) population, the detection rate for the GG genotype was significantly higher than that in the present study.

\section{Serum IL-18 levels}

The normality test indicated that the IL-18 distribution was abnormal (Kolmogorov-Smirnov test, $p<0.001$ ) and it was therefore presented as median \pm IQR (Table
$5)$. The overall concentration of serum IL-18 among healthy controls, CHB patients, and LC patients was $114.40 \pm 66.54 \mathrm{ng} / \mathrm{L}, 72.67 \pm 42.02 \mathrm{ng} / \mathrm{L}$, and $66.13 \pm$ $41.59 \mathrm{ng} / \mathrm{L}$, respectively. According to the Kruskal-Wallis test, a significant difference in serum IL-18 levels among groups was found $(p<0.001)$. Following the StudentNewman-Keuls test, the serum IL-18 concentration in the CHB and LC groups was found to be significantly lower than in the control group (both $p<0.001$ ), while no significant difference was observed between the patient groups $(p=0.390)$. A similar situation was also found when comparing the serum IL-18 levels among individuals with the same genotype in all three groups: they were significantly lower in the $\mathrm{CHB}$ and LC group, regardless of the AA, AC, and CC genotypes of $-607 \mathrm{C} / \mathrm{A} \mathrm{SNP}$ or the GG and GC genotypes of $-137 \mathrm{G} / \mathrm{C}$ SNP (the statistic was not significant in the $\mathrm{CC}$ genotype, but a similar trend was observed). However, when considering the possible difference of IL-18 concentration among different genotypes in the same group, no significant differences were found, indicating that serum IL-18 levels were not associated with the $-607 \mathrm{C} / \mathrm{A}$ and $-137 \mathrm{G} / \mathrm{C}$ polymorphisms . Details are presented in Table 5.

\section{Discussion}

IL-18, being part of the pro-inflammatory cytokine network, is an essential mediator in innate and adaptive

Table 4. Comparison of Genotype and Allele Frequencies in the Control Subjects of our Study and that from the HapMap Project

\begin{tabular}{|c|c|c|c|c|c|c|c|c|}
\hline \multirow{2}{*}{$\begin{array}{l}\text { SNPs } \\
-607 \mathrm{C} / \mathrm{A}(\mathrm{rs} 1946518)\end{array}$} & \multirow{2}{*}{ Samples, $\mathrm{n}$} & \multicolumn{4}{|c|}{ Genotype frequency, n (\%) } & \multicolumn{3}{|c|}{ Allele frequency, n (\%) } \\
\hline & & AA & $\mathrm{AC}$ & $\mathrm{CC}$ & $P$ values & A & $\mathrm{C}$ & $P$ values \\
\hline Present study & 160 & $40(25.0)$ & $73(45.6)$ & $47(29.4)$ & & $153(47.8)$ & $167(52.2)$ & \\
\hline CEU* & 111 & $18(16.2)$ & $51(45.9)$ & $42(37.8)$ & 0.150 & $87(39.2)$ & $135(60.8)$ & 0.047 \\
\hline $\mathrm{HCB}^{*}$ & 43 & $16(37.2)$ & $19(44.2)$ & $8(18.6)$ & 0.192 & $51(59.3)$ & $35(40.7)$ & 0.058 \\
\hline $\mathrm{JPT}^{*}$ & 86 & $29(33.7)$ & $41(47.7)$ & $16(18.6)$ & 0.129 & $99(57.6)$ & $73(42.4)$ & 0.039 \\
\hline YRI* & 113 & $14(12.4)$ & $50(44.2)$ & $49(43.4)$ & 0.010 & $78(34.5)$ & $148(65.5)$ & 0.002 \\
\hline$-137 \mathrm{C} / \mathrm{G}(\mathrm{rs} 187238)$ & & GG & GC & $\mathrm{CC}$ & $P$ values & G & $\mathrm{C}$ & $P$ values \\
\hline Present study & 160 & $103(64.4)$ & $52(32.5)$ & $5(3.0)$ & & $258(80.6)$ & $62(19.4)$ & \\
\hline EUR* & 24 & $10(41.7)$ & $14(58.3)$ & $0(0.0)$ & 0.046 & $34(70.8)$ & $14(29.2)$ & 0.118 \\
\hline AFR* & 23 & $16(69.6)$ & $7(30.4)$ & $0(0.0)$ & 1.000 & $39(84.8)$ & $7(15.2)$ & 0.500 \\
\hline $\mathrm{CHN}^{*}$ & 21 & $17(81.0)$ & $4(19.0)$ & $0(0.0)$ & 0.333 & $38(90.5)$ & $4(9.5)$ & 0.120 \\
\hline $\mathrm{HCH}^{\dagger}$ & 300 & $202(67.3)$ & $90(30.0)$ & $8(2.7)$ & 0.804 & $494(82.3)$ & $106(17.7)$ & 0.523 \\
\hline
\end{tabular}

*Data from HapMap Project; $\dagger$ Data from previous reports; CEU, Utah residents with northern and western European ancestry; HCB, Han Chinese in Beijing, China; JPT, Japanese in Tokyo, Japan; YRI, Yoruba in Ibadan, Nigeria; EUR, European American descent; AFR, African American descent; CHN, Chinese descent; HCH, Han Chinese in Hubei province, China

Table 5. The Association between IL-18 Gene Polymorphisms and Serum IL-18 Levels (median \pm IQR, ng/L) in Cases and Healthy Controls

\begin{tabular}{|c|c|c|c|c|c|c|c|c|c|}
\hline \multirow[t]{2}{*}{ Groups } & \multirow[t]{2}{*}{ Overall } & \multicolumn{4}{|c|}{$-607 \mathrm{C} / \mathrm{A}(\mathrm{rs} 1946518)$} & \multicolumn{4}{|c|}{$-137 \mathrm{G} / \mathrm{C}(\mathrm{rs} 187238)$} \\
\hline & & $\overline{\mathrm{AA}}$ & $\mathrm{AC}$ & $\mathrm{CC}$ & $P$-values & GG & $\mathrm{GC}$ & $\mathrm{CC}$ & $\overline{\text { values }^{\mathrm{a}}}$ \\
\hline Controls $(n=160)$ & $114.40 \pm 66.54$ & $108.83 \pm 101.78(40)$ & $109.79 \pm 73.94(73)$ & $119.02 \pm 43.65(48)$ & 0.609 & $121.90 \pm 66.83(103)$ & $104.21 \pm 58.41(52)$ & $108.06 \pm 99.24(5)$ & 0.198 \\
\hline CHB $(n=129)$ & $72.67 \pm 42.02$ & $76.90 \pm 38.79(32)$ & $69.40 \pm 39.86(58)$ & $79.98 \pm 47.49(39)$ & 0.396 & $72.96 \pm 44.95(100)$ & $71.13 \pm 37.50(27)$ & $91.90 \pm 28.85(2)$ & 0.620 \\
\hline $\mathrm{LC}(\mathrm{n}=86)$ & $66.13 \pm 41.59$ & $73.73 \pm 44.04(22)$ & $64.40 \pm 38.85(39)$ & $63.44 \pm 46.54(25)$ & 0.401 & $64.40 \pm 41.83(69)$ & $74.69 \pm 36.68(16)$ & $-(1)$ & $0.196^{c}$ \\
\hline$P$ values ${ }^{\mathrm{b}}$ & $<0.001$ & 0.001 & $<0.001$ & $<0.001$ & & $<0.001$ & $<0.001$ & $0.699^{c}$ & \\
\hline
\end{tabular}

CHB chronic hepatitis B, LC liver cirrhosis, IQR interquartile range; ${ }^{a}$ Kruskal-Wallis test: comparing the difference of serum IL-18 levels in different genotypes among the same group subjects; ${ }^{\mathrm{b}}$ Kruskal-Wallis test: comparing the difference of serum IL-18 levels in the three group subjects among the individuals with the same genotype; ${ }^{c}$ Mann-Whitney U tset: as only one subject with CC genotype was observed in the LC group, Mann-Whitney U test was used to compare the difference of serum IL-18 levels between the $-137 \mathrm{G} / \mathrm{C}$ SNP GG and GC genotypes in LC group and difference of serum IL-18 levels between the CHB and control groups in the CC genotype 
immunity. As mentioned above, several SNPs in the IL-18 gene promoter region have been found and are predicted to influence the expression of IL-18 (Giedraitis et al., 2001). Such influence may further lead to an alteration in an individual's immune status, consequently making carriers more or less susceptible to the disease. This may be the underlying mechanism of the observed relationship between IL-18 promoter polymorphisms and diverse diseases. HCC, a common malignancy worldwide, is one of the most frequent and worst endstage complications of HBV infection (Yu and Chen, 1994). IL-18 polymorphisms have been found to be significantly associated with this malignancy (Kim et al., 2009). As is well known, CHB, LC, and HCC are progressive stages of chronic HBV infection (Yin et al., 2011); however, the attention given to $\mathrm{LC}$ is lacking thus far, with only two studies regarding IL-18 polymorphisms and LC risk have been conducted to date (Migita et al., 2009; Karra et al., 2015); and recent studies have revealed that IL-18 in urine could serve as a diagnostic and prognostic marker for cirrhotic patients with acute renal failure (Qasem et al., 2014), but not much attention has been paid to the relationship between IL-18 polymorphisms with its serum expression and risk of CHB and HBV-related LC. Therefore, this study assesses their association, mainly focusing on CHB- and HBV-related LC patients.

In the present study, the IL-18 gene $-137 \mathrm{G} / \mathrm{C}$ SNP was found to be significantly associated with both HBV-related liver diseases. The presence of the GC genotype and C allele of this polymorphism was observed to significantly decrease the risk of CHB- and HBV-related LC. A similar association was also noted in the A-607C-137 haplotype. However, these results are just partially consistent with the previous studies (Migita et al., 2009; Karra et al., 2015). Most studies regarding IL-18 polymorphisms have revealed a significant correlation between the $\mathrm{C}$ allele of $-137 \mathrm{G} / \mathrm{C}$ and risk of CHB and LC (Zhang et al., 2005; Migita et al., 2009; Cheong et al., 2010), which is in agreement with our findings. Nevertheless, studies by Migita et al. (Migita et al., 2009) and Cheong et al. (2010) have also suggested a higher detection rate of the -607 C/A AA genotype in CHB patients. Further, a study by Hirankarn et al. (2007) demonstrated that only the A/A genotype at position - 607 in the IL-18 gene was associated with CHB. Even in studies carried out in the same country (China), different findings have been reported. Zhang et al. (2005) found that subjects with the $C$ allele at position -137 of the IL-18 gene may be protected against HBV infection, while Li et al. (2012a) noted that the AA genotype and the A allele of the IL-18 $-607 \mathrm{C} / \mathrm{A}$ are associated with an increased risk of $\mathrm{CHB}$.

The possible underlying mechanism of these controversial results may attribute to the differences in the IL-18 genetic background among diverse ethnicities. Results from our comparison of genotype and allele frequencies in the healthy control subjects in the present study with those from the HapMap project provided evidence for this effect. In the current study, the A and $\mathrm{C}$ allele frequencies in the IL-18 -607C/A SNP were significantly different from all those from the HapMap project except for the HCB population ( $p=0.058$ ), which may be why the most inconsistent results were found in the -607C/A SNP. Since the Guangxi Zhuang population is also a minority population, this may be why our results were inconsistent with those of previous Chinese studies.

With respect to the serum IL-18 levels, these were found to be significantly lower in CHB and LC patients compared with healthy controls. Our results are neither consistent with previous reports which showed a null influence between CHB and IL-18 concentration (Wen et al., 2001) nor are they in agreement with the findings in HCC suggesting higher IL-18 levels (Kim et al., 2009), indicating a controversial result regarding the serum IL-18 levels. In fact, according to Wen et al. (Wen et al., 2001), serum IL-18 levels showed a dramatic difference during the various stages of HBV infection; the highest IL-18 level was found in the fulminant hepatitis group and the lowest in an asymptomatic carrier group; no significant difference between CHB and normal controls was noted. Similar findings were also observed by $\mathrm{Wu}$ et al. (Wu et al., 2013), who suggested a significantly higher IL-18 level in acute hepatitis B patients than in both normal controls and CHB patients. This study further pointed out that even during the same CHB state, IL-18 concentration could be different, the highest during the immune clearance state $(230.35 \mathrm{pg} / \mathrm{mL})$ and the lowest during the immune tolerance $(63.5 \mathrm{pg} / \mathrm{mL})$ and inactive-carrier $(58.75 \mathrm{pg} /$ $\mathrm{mL}$ ) states. With respect to $\mathrm{LC}$, the only available study also indicated that there was no correlation between IL-18 levels and Ishak score or fibrosis (Akcam et al., 2012). Based on these results, a rise in IL-18 was mainly observed in the acute phase of the disease, the significantly lower serum IL-18 levels found herein may have been due to the inclusion of subjects with chronic disease. Unfortunately, complete data on disease stage was not available for every subject, and therefore a subgroup analysis could not be performed.

Further, when considering the relationship between $-607 \mathrm{C} / \mathrm{A}$ and $-137 \mathrm{G} / \mathrm{C}$ polymorphisms and IL-18 serum level, no association could be found. This was inconsistent with previous findings by Giedraitis et al. and Jiang et al. (Giedraitis et al., 2001; Jiang et al., 2014), both suggested that polymorphisms at positions -137 had clear promoter activity and were able to influence the expression of IL18. However, as IL-18 is mainly secreted by activated macrophages (Pirhonen et al., 1999), in addition to gene polymorphisms, the expression of IL-18 is also associated with other factors such as stimulations from the environment and an idividual's immune state. These factors may have a stronger influence on the expression of IL-18, and may thus mask the effect of IL-18 gene polymorphisms. Another explanation for this maybe the small enrollment sample numbers in each subgroup of our study, since these two SNPs could change the IL-18 gene expression.

In conclusion, the present study showed that the $-137 \mathrm{G} /$ $\mathrm{C}$ polymorphism of the IL-18 gene was associated with a decreased risk of CHB- and HBV-related LC, indicating that the $-137 \mathrm{C}$ allele in IL-18 gene may play a protective role in the development of $\mathrm{HBV}$-related diseases. The serum IL-18 levels were significant decreased in CHB and LC patients, but no association between $-607 \mathrm{C} / \mathrm{A}$ 
and $-137 \mathrm{G} / \mathrm{C}$ SNPs in the IL-18 promoter region and its expression were found. Considering the relatively small sample size of this study, further studies with larger sample size are warranted.

\section{Acknowledgements}

This research was supported by the Youth Science Foundation of Guangxi Medical University (GXMUYSF201334) and the 2015 Innovation Project of Guangxi Graduate Education (YCBZ2015027).

\section{References}

Akcam FZ, Tigli A, Kaya O, et al (2012). Cytokine levels and histopathology in chronic hepatitis B and chronic hepatitis C. J Interferon Cytokine Res, 32, 570-4.

Cheong JY, Cho SW, Oh B, et al (2010). Association of interleukin-18 gene polymorphisms with hepatitis B virus clearance. Dig Dis Sci, 55, 1113-9.

El-Serag HB, Rudolph KL (2007). Hepatocellular carcinoma: epidemiology and molecular carcinogenesis. Gastroenterology, 132, 2557-76.

Giedraitis V, He B, Huang WX, et al (2001). Cloning and mutation analysis of the human IL-18 promoter: a possible role of polymorphisms in expression regulation. $J$ Neuroimmunol, 112, 146-52.

Gracie JA, Koyama N, Murdoch J, et al (2005). Disease association of two distinct interleukin-18 promoter polymorphisms in Caucasian rheumatoid arthritis patients. Genes Immun, 6, 211-6.

Hirankarn N, Manonom C, Tangkijvanich $P$, et al (2007). Association of interleukin-18 gene polymorphism (-607A/A genotype) with susceptibility to chronic hepatitis B virus infection. Tissue Antigens, 70, 160-3.

Hoshino T, Wiltrout RH, Young HA (1999). IL-18 is a potent coinducer of IL-13 in NK and T cells: a new potential role for IL-18 in modulating the immune response. J Immunol, 162, 5070-7.

Jiang H, Cao H, Liu G, et al (2014). IL-18 promoter -137G/C polymorphism correlates with chronic hepatitis B and affects the expression of interleukins. Acta Virol, 58, 28-33.

Karra VK, Gumma PK, Chowdhury SJ, et al (2015). IL-18 polymorphisms in hepatitis B virus related liver disease. Cytokine, 73, 277-82.

Kim YS, Cheong JY, Cho SW, et al (2009). A functional SNP of the Interleukin-18 gene is associated with the presence of hepatocellular carcinoma in hepatitis B virus-infected patients. Dig Dis Sci, 54, 2722-8.

Kruse S, Kuehr J, Moseler M, et al (2003). Polymorphisms in the IL 18 gene are associated with specific sensitization to common allergens and allergic rhinitis. J Allergy Clin Immunol, 111, 117-22.

Lavanchy D (2004). Hepatitis B virus epidemiology, disease burden, treatment, and current and emerging prevention and control measures. J Viral Hepat, 11, 97-107.

Li N, Gao YF, Zhang TC, et al (2012a). Relationship between interleukin 18 polymorphisms and susceptibility to chronic hepatitis B virus infection. World J Hepatol, 4, 105-9.

Li Y, Shi Y, Chen J, et al (2012b). Association of polymorphisms in interleukin-18 and interleukin-28B with hepatitis B recurrence after liver transplantation in Chinese Han population. Int J Immunogenet, 39, 346-52.

Lin YJ, Wan L, Lee CC, et al (2007). Disease association of the interleukin-18 promoter polymorphisms in Taiwan Chinese systemic lupus erythematosus patients. Genes Immun, 8 , 302-7.

McKillop IH, Moran DM, Jin X, et al (2006). Molecular pathogenesis of hepatocellular carcinoma. J Surg Res, 136, 125-35.

Migita K, Sawakami-Kobayashi K, Maeda Y, et al (2009). Interleukin-18 promoter polymorphisms and the disease progression of Hepatitis B virus-related liver disease. Transl Res, 153, 91-6.

Mojtahedi Z, Naeimi S, Farjadian S, et al (2006). Association of IL-18 promoter polymorphisms with predisposition to Type 1 diabetes. Diabet Med, 23, 235-9.

Moradpour D, Blum HE (2005). Pathogenesis of hepatocellular carcinoma. Eur J Gastroenterol Hepatol, 17, 477-83.

Motavaf M, Safari S, Alavian SM (2014). Interleukin 18 gene promoter polymorphisms and susceptibility to chronic hepatitis B infection: a review study. Hepat Mon, 14, 19879.

Nakanishi K, Yoshimoto T, Tsutsui H, et al (2001). Interleukin-18 regulates both Th1 and Th2 responses. Annu Rev Immunol, 19, 423-74.

Okamura H, Tsutsi H, Komatsu T, et al (1995). Cloning of a new cytokine that induces IFN-gamma production by $\mathrm{T}$ cells. Nature, 378, 88-91.

Okamura H, Tsutsui H, Kashiwamura S, et al (1998). Interleukin-18: a novel cytokine that augments both innate and acquired immunity. Adv Immunol, 70, 281-312.

Perrillo RP (2002). How will we use the new antiviral agents for hepatitis B? Curr Gastroenterol Rep, 4, 63-71.

Pirhonen J, Sareneva T, Kurimoto M, et al (1999). Virus infection activates IL-1 beta and IL-18 production in human macrophages by a caspase-1-dependent pathway. J Immunol, 162, 7322-9.

Qasem AA, Farag SE, Hamed E, et al (2014). Urinary biomarkers of acute kidney injury in patients with liver cirrhosis. ISRN Nephrol, 2014, 376795.

Stephens M, Smith NJ, Donnelly $P$ (2001). A new statistical method for haplotype reconstruction from population data. Am J Hum Genet, 68, 978-89.

Taheri M, Hashemi M, Eskandari-Nasab E, et al (2012). Association of -607 C/A polymorphism of IL-18 gene (rs1946518) with breast cancer risk in Zahedan, Southeast Iran. Prague Med Rep, 113, 217-22.

Tsai HT, Hsin CH, Hsieh YH, et al (2013). Impact of interleukin-18 polymorphisms $-607 \mathrm{~A} / \mathrm{C}$ and $-137 \mathrm{G} / \mathrm{C}$ on oral cancer occurrence and clinical progression. PLoS One, $\mathbf{8}, 83572$.

Tuncbilek S (2014). Relationship between cytokine gene polymorphisms and chronic hepatitis B virus infection. World J Gastroenterol, 20, 6226-35.

Wang KX, Peng JL, Wang XF, et al (2003). Detection of T lymphocyte subsets and mIL-2R on surface of PBMC in patients with hepatitis B. World J Gastroenterol, 9, 2017-20.

Wen W, Zhang L, Xiao H (2001). [The transcription and expression of IL-18 gene in HBV infectors]. Zhonghua $Y i$ Xue Za Zhi, 81, 655-8.

World Health Organization. Hepatitis B. World Health Organization Fact Sheet 204 (Revised October 2000). WHO Web site. 2000. http://who.int/inf-fs/en/fact204.html.

Wu DL, Xu GH, Lu SM, et al (2013). Correlation of AIM2 expression in peripheral blood mononuclear cells from humans with acute and chronic hepatitis B. Hum Immunol, 74, 514-21.

Wu L, Chen L, Zhou L, et al (2011). Association of interleukin 18 gene promoter polymorphisms with HBV recurrence after liver transplantation in Han Chinese population. Hepat Mon, 11, 469-74.

Xia $P$, Zhou M, Dong DS, et al (2014). Association of 
Yu Lu et al

polymorphisms in interleukin-18 and interleukin-28B genes with outcomes of hepatitis B virus infections: a metaanalysis. Tumour Biol, 35, 1129-37.

Xin-min GJ-mZY-IDHTHXYY (2010). Relationship between HBV infection and polymorphism of IL-18 promoter gene among three minority populations in Yunnan province. Chin J Clinicians ( Electronic Edition), 4, 1525-31.

Yin J, Xie J, Liu S, et al (2011). Association between the various mutations in viral core promoter region to different stages of hepatitis B, ranging of asymptomatic carrier state to hepatocellular carcinoma. Am J Gastroenterol, 106, 81-92.

Yu MW, Chen CJ (1994). Hepatitis B and C viruses in the development of hepatocellular carcinoma. Crit Rev Oncol Hematol, 17, 71-91.

Zhang PA, Wu JM, Li Y, et al (2005). Association of polymorphisms of interleukin-18 gene promoter region with chronic hepatitis B in Chinese Han population. World J Gastroenterol, 11, 1594-8.

Zhang Y,Li Y, Ma Y, et al (2011). Dual effects of interleukin-18: inhibiting hepatitis B virus replication in HepG2.2.15 cells and promoting hepatoma cells metastasis. Am J Physiol Gastrointest Liver Physiol, 301, G565-73.

Zhou Y, Yamaguchi E, Hizawa N, et al (2005). Roles of functional polymorphisms in the interleukin-18 gene promoter in sarcoidosis. Sarcoidosis Vasc Diffuse Lung Dis, 22, 105-13. 